\title{
Note of the Editors
}

\section{Vincenzo Crupi • Branden Fitelson • Ole Hjortland • Florian Steinberger}

Received: 3 October 2013/Accepted: 3 October 2013/Published online: 16 October 2013 (C) Springer Science+Business Media Dordrecht 2013

This special issue of Erkenntnis collects a selection of papers from participants of the 9th Formal Epistemology Workshop (FEW), held at the Munich Center for Mathematical Philosophy, May 29-June 1, 2012. We would like to express our gratitude to all the people who contributed in making the workshop a great event on all accounts: Hannes Leitgeb, all speakers, discussants, and attendees, Roland Pöllinger and the MCMP staff.

V. Crupi $(\bowtie) \cdot$ B. Fitelson · O. Hjortland · F. Steinberger Turin, Italy

e-mail: vincenzo.crupi@unito.it 